\title{
A simple circuit for administering electric shock to rats
}

\author{
MELVIN L. GOLDSTEIN \\ Indiana University at Kokomo, Kokomo, Indiana 46901
}

\begin{abstract}
A circuit for administering electric shock to rats in acquired drive experiments is described. The circuit approximates the matched impedance shock source.
\end{abstract}

The shock circuit used in the original acquired drive study (Goldstein, 1960) is shown in Figure 1. The circuit corresponds most closely to the matched impedance shock source described by Campbell and Teghtsoonian (1958). It does not contain a commutator, as did the

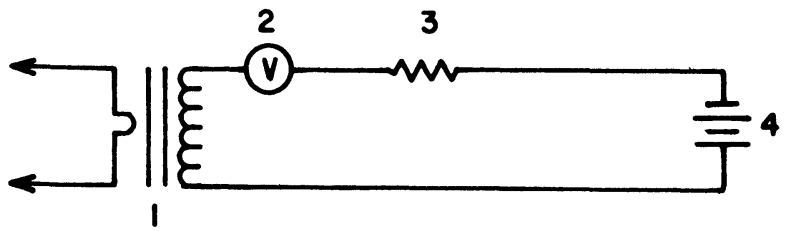

Figure 1. Circuit diagram for the shock circuit used in the Gold stein (1960) experiment. (1) Step-up transformer, 0-1,200 V. (2) Voltmeter. (3) Fixed resistor, 250,000 ohms. (4) Grid. circuits described by Wyckoff and Page (1954) and Skinner and Campbell (1947). The circuit is an effective source of electric shock which serves as the UCS in acquired drive, or classically conditioned fear, studies.

\section{REFERENCES}

Campbell, B. A., \& Teghtsoonian, R. Electrical and behavioral effects of different types of shock stimuli on the rat. Journal of Comparative and Physiological Psychology, 1958, 51, 185-192.

Goldstein, M. L. Acquired drive strength as a joint function of shock intensity and number of acquisition trials. Journal of Experimental Psychology, 1960, 60, 349-358.

Skinner, B. F., \& Campbell, S. L. An autonomic shocking-grid apparatus for continuous use. Journal of Comparative and Phy siological Psy chology, 1947, 40, 305-307.

Wyckoff, L. B., \& Page, H. A. A grid for administering shock. American Journal of Psychology, 1954, 67, 154.

(Received for publication April 24, 1975.) 